\title{
Fetal gunshot of the chest: An unprecedented surgical encounter
}

\author{
Mohammad Hanif Beg, Wasif M Ali, Abdus Samad \\ Kumar Gauraw, Shahbaaz Alam, Shaquib
}

\begin{abstract}
Introduction: Fetal gunshot injuries are rare and more often than not are concealed by parents because of the medico-legal issues and hence its incidence far exceeds the number of the cases reported in the world literature. It is very unusual to incidentally detect bullet in the chest wall after 10 years of injury. Case Report: We are presenting a rare case of 10-years-old boy, who was admitted for operation of chronic suppurative otitis media (CSOM), but during routine pre-anesthetic check up, the chest $X$ ray of the patient showed a radio opaque shadow in the right hemithorax located subcutaneously. The bullet was removed under local anesthesia and the patient was later operated for CSOM. Conclusion: A long asymptomatic period without a previous history of gunshot injury and absence of any scar suggestive of entry wound on examination makes this case interesting and unique as this
\end{abstract}

Mohammad Hanif Beg${ }^{1}$, Wasif M.Ali ${ }^{2}$, Abdus Samad ${ }^{3}$, Kumar Gauraw ${ }^{4}$, Shahbaaz Alam ${ }^{4}$, Shaquib ${ }^{4}$

Affiliations: ${ }^{1}$ Professor, Cardiothoracic Surgery unit, Department of Surgery, J.N.M.C.AMU, Aligarh, U.P., India; ${ }^{2}$ Assistant Professor, Department of Surgery, J.N.M.C.AMU, Aligarh, U.P., India PIN-202002; ${ }^{3}$ Senior Resident, Department of surgery, J.N.M.C.AMU, Aligarh, U.P., India; ${ }^{4}$ MBBS, Junior Resident, Department of surgery, J.N.M.C. AMU, Aligarh, U.P., India.

Corresponding Author: Prof. Mohammad Hanif Beg, Cardiothoracic surgery unit, Department of surgery, J.N.M.C. AMU, Aligarh, U.P., India; Ph: 09760264780; Email: mhbeg@rediffmail.com

Received: 4 October 2010

Accepted: 26 November 2010

Published: 01 August 2011 could happen if the patient had sustained the gunshot in utero.

Keywords: Chest, Gunshot, Fetus

$* * * * * * * *$

Beg MH, Ali WM, Samad A, Gauraw K, Alam S, Shaquib. Fetal gunshot of the chest: An unprecedented surgical encounter. International Journal of Case Reports and Images 2011;2(8):1-4.

\section{$* * * * * * * * *$}

doi:10.5348/ijcri-2011-08-46-CR-1

\section{INTRODUCTION}

Missile injuries in the form of the gunshot and war projectiles are very common in the modern era in every corner of the world because of the political unrest and ever increasing civilian violence. There is a paucity of case reports in literature where pregnant women have sustained gunshot along with fetus. There are only sixty two cases reported so far in the literature including the one we are reporting [1-4].

These injuries are quiet obvious to the patients and their attendants. Even if the patient refuses to admit any such previous encounter, it is very uncommon that injury remains unnoticed, without any consequences to mother and fetus. The reason for such a denial mainly includes medico-legal issues, for instance in some of the cases it may be the result of the suicide attempt which in itself is a punishable crime in many countries and when the death of the fetus occurs then this amounts to a culpable offence. Here we present a case of mother who refused to admit any such encounter but there was a scar mark on the left side four $\mathrm{cm}$ lateral to a vertical midline abdominal incision. Her 10-year-old son was incidentally found to 
have a bullet in chest X-ray (PA view), while he was being routinely evaluated for preanaesthetic check up for CSOM. The bullet was later recovered after operation under local anesthesia.

\section{CASE REPORT}

A 10-year-old young boy was admitted in Otorhinolaryngology ward to undergo operation for chronic suppurative otitis media (CSOM). During the routine preanaesthetic check up the chest X-ray showed a radio opaque shadow in the right hemithorax, anterior to the inferior angle of the right scapula (Figure 1) for which the patient was referred to the division of Cardio Thoracic and Vascular Surgery (CTVS) for expert opinion regarding the management.

The patient's mother gave a history of gradual enlargement of the swelling at the back of right chest wall of her son since birth. There was no history of any previous gunshot injury. On examination a hard and mobile swelling of size $2.5 \times 1 \mathrm{~cm}$ was palpable in the subcutaneous plane anterior to the inferior angle of the scapula. There was no scar mark suggestive of any entry wound either anteriorly or posteriorly on the chest wall. We thought it to be a rare case of in-utero injury so we took elaborate history from his mother regarding any such encounter during her pregnancy but she denied. On examination of the mother we found a scar mark of $3 \times 0.5 \mathrm{~cm}$ present on the left side of the abdomen, four $\mathrm{cm}$ lateral to a vertical midline abdominal incision. She refused to be questioned about the scar in the abdomen and started uncooperating so we did not inquire further.

The boy was operated under local anesthesia on the same day and bullet of size $1.2 \times 1 \mathrm{~cm}$, weighing 100 grams was recovered (Figure 2,3). The wound was sutured primarily. The patient was referred back to Otorhinolaryngology department for further management.

\section{DISCUSSION}

The first recorded case of gunshot of the fetus appeared in 1845 [1]. The incidence of the gunshot injury to the fetus probably far exceeds the reported number of cases as most of the time the family conceals the fact as has happened in our case because of medico-legal issues.

Kobak and Hurwitz et al. in 1954 were able to collect only 31 cases and added two new cases. By 1964 only 45 reports were there in English literature. Later Buchsbaum et al. [2] and Houel et al. [3] enumerated 54 cases of gunshot to the abdomen and 10 cases of the war projectile injuries of the gravid uterus. Recent literature shows that there was addition of eight more cases of gunshot abdomen of pregnant female including the one reported by us taking the total to 62 cases reported so far [4].

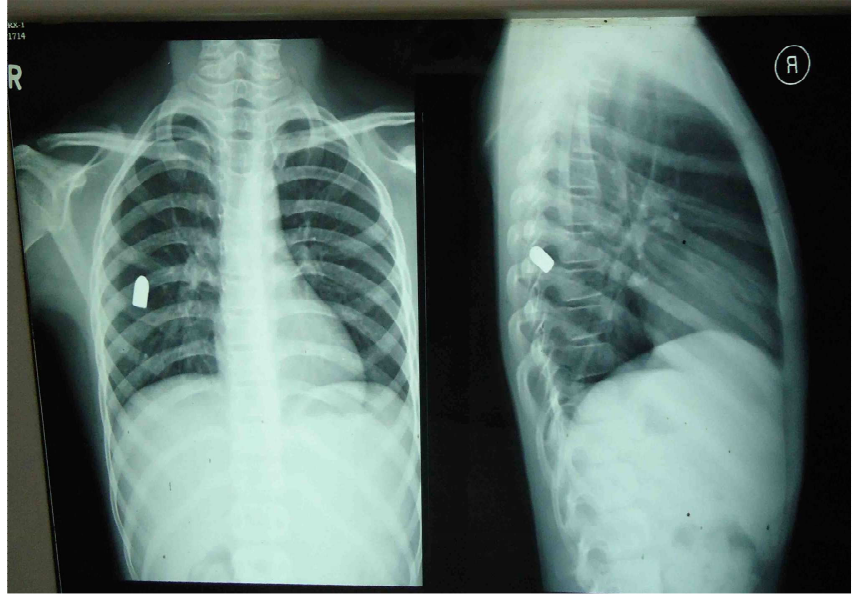

Figure 1: $\mathrm{X}$-ray chest $\mathrm{PA}$ and right lateral revealing radio opaque shadow (bullet)

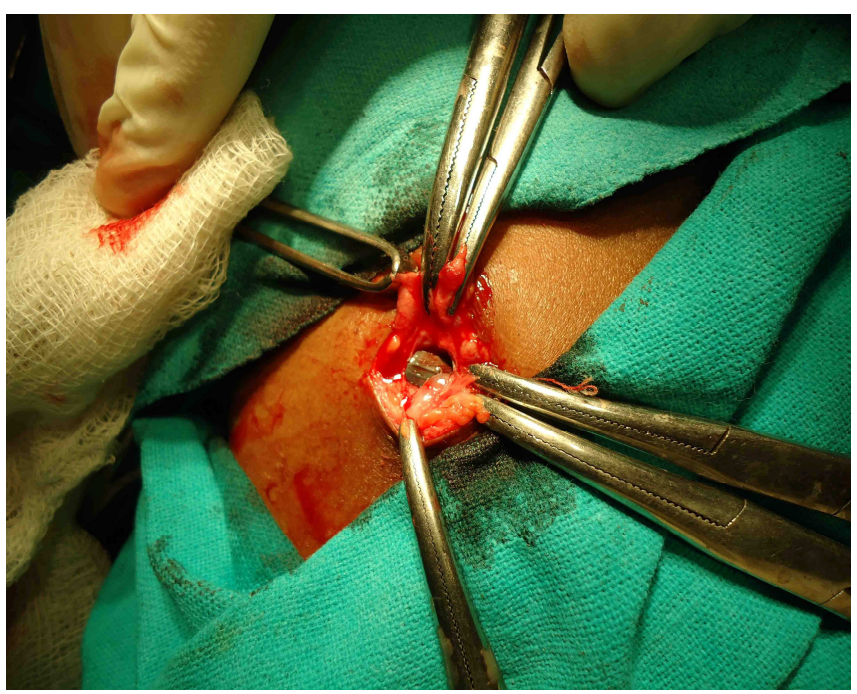

Figure 2: Operative photograph revealing bullet in the capsule.

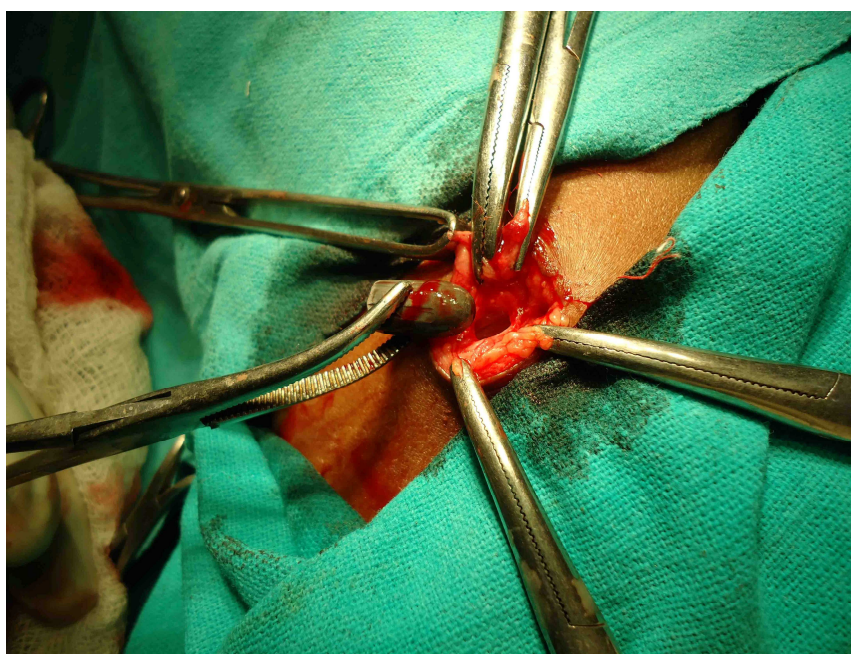

Figure 3: Operative photograph showing removed bullet. 
The mortality rate for the civilian gunshot wound is 10-20\% but there have been no maternal deaths reported from gunshot wounds of the pregnant uterus since 1912 [5], because during late pregnancy the abdominal viscera particularly the small bowel is pushed and compressed upwards by the gravid uterus. Moreover, the gravid uterus diminishes the velocity of the missile and thus acts as a shield, both for the mother and the fetus. However, associated injuries have been reported in $24 \%$ [6], 27\% [1] and 38\% [2] of the victims in three series of gunshot wounds of the pregnant uterus. The overall prognosis for the mother remains excellent as has happened in our case where mother remained normal while the fetus suffered bullet injury.

The management of such cases is still a matter of debate. Since the number of such cases are scanty and there is absence of any long term studies regarding the best management protocol, the surgeon should act prudently using his clinical acumen in the best interest of the life of mother and the fetus along with due consideration to the future child bearing capacity of the mother. There are two issues in the management of these cases. The first is about the optimal management of the mother and now the consensus opinion seems to be that all such patients should be subjected to immediate laparotomy as there is probability of intraabdominal hemorrhage or damage to other vital structures $[1,3,6]$. The second is about the injured gravid uterus. Some surgeons like Eckerling et al. [7] have opinioned that immediate caesarean section should be performed irrespective of the viability of the fetus particularly if the patient is in labor, in order to avoid rupture of the injured uterus and to spare the patient from the additional heavy physical strain of labor during the early postoperative period [7]. Kobak et al. [5] in his case series of 15 patients showed that wounded pregnant uterus can withstand normal labor without uterine rupture and caesarian section is not mandatory in all cases. Later other reports supported his views and opinioned that if the fetus was viable (more than 28 weeks or 1000 gms) and alive, immediate abdominal delivery and immediate treatment of the remediable injuries to the fetus should be done for better fetal salvage but if the fetus is not viable and uterine damage is not extensive than suturing uterine wound and waiting for the vaginal delivery should be a favored approach [9].

Many studies are underway to know the precise mechanism of the scar less wound healing in the fetus. Earlier it was considered that the fetal wound environment was different from adult tissue injury like there is low $\mathrm{pO} 2$, absence of the polymorphonuclear leucocytes and immunoglobulins and there was warm and sterile amniotic fluid. Later studies showed that adult skin transplanted to the fetus heals with scar formation in the lambs despite exposure to the same intrauterine environment. This led to the conclusion that the factors responsible for scar less healing were inherent to the fetal skin. Recent studies of Mark et al. [9] have shown that embryonic wound healing shows less differentiated inflammatory response and there is change in the growth factor profile with low levels of TGF $\beta 1$ and TGF $\beta 2$ and platelet derived growth factor (PDGF) with high levels of TGF 33 . Moreover, fibroblasts with high synthetic capabilities deposit collagen rapidly and without scarring. Similar scar profile as in the fetal wound has been seen in old age due to age related changes in the scar quality and inflammatory profile [10].

The research has lead to the development of novel pharmaceutical molecules which markedly improve or completely prevent the scarring. Some of them have entered the human clinical trials but it will take time before their widespread use provides benefit of preventing complications due to scarring [9]. In the coming years the possibility of use of such novel therapeutic agents for avoiding scars will also have to be considered when there is no obvious reason for finding any foreign object inside the body, as in our case. In the present case there is no reason to consider such a diagnoses as these agents are still experimental and babies and old people with scar less healing are very rare cases reported in the literature.

\section{CONCLUSION}

The case presented here is unique in the sense that besides being rare there is no history forthcoming, of bullet injury to either the mother or the patient. This highlights the fact that the patient and attendants may sometimes conceal certain important facts because of the medico-legal issues. Therefore, once suspicion arises surgeons in such cases must examine both the patient and the mother to ascertain the cause of bullet injury while taking immense care that the patient does not turn hostile.

$* * * * * * * * *$

\section{Author Contributions}

Mohammad Hanif Beg - Substantial contributions to conception and design, Analysis of data, Interpretation of data, Drafting the article, Revising it critically for important intellectual content, Final approval of the version to be published

Wasif M. Ali - Substantial contributions to conception and design, Acquisition of data, Interpretation of data, Drafting the article, Revising it critically for important intellectual content, Final approval of the version to be published

Abdus Samad - Acquisition of data, Interpretation of data, Drafting the article, Revising it critically for important intellectual content, Final approval of the version to be published

Kumar Gauraw - Acquisition of data, Interpretation of data, Drafting the article, Final approval of the version to be published

Shahbaaz Alam - Acquisition of data, Interpretation of data, Drafting the article, Final approval of the version 
to be published

Shaquib - Acquisition of data, Interpretation of data, Drafting the article, Final approval of the version to be published

\section{Guarantor}

The corresponding author is the guarantor of submission.

\section{Conflict of Interest}

Authors declare no conflict of interest.

\section{Copyright}

(C) Mohammad Hanif Beg et al. 2011; This article is distributed under the terms of Creative Commons attribution 3.0 License which permits unrestricted use, distribution and reproduction in any means provided the original authors and original publisher are properly credited. (Please see www.ijcasereportsandimages.com /copyright-policy.php for more information.)

\section{REFERENCES}

1. Beatle, JF, Daly RF. Gunshot wound of the pregnant uterus. Am J Obstetrics Gynaec. 1960;80:772-4

2. Buchsbaum HJ. accidental injury complicating pregnancy. Am J Obstet Gynec. 1968;102:752-69

3. Houel E, Gares R, Mesnard F. Les plaics de l'uterus gravid. Rev Fr Gynec Obst. 1959;54:7-20.

4. Wilson F, Swartz DP. Gunshot and war projectile wounds of the gravid uterus. Case report and review of literature. J Natl Med Assoc. 1972 January;64(1):8-13.

5. Wilson H, Sherman R. Civilian penetrating wounds of the abdomen - Factors in mortality and differences from military wounds in 494 cases. Ann Surg. 1961;153:639-46

6. Kobak AJ, Hurwitz C H. Gunshot wounds of the pregnant uterus. Review of the literature and two case reports. Obstet Gynec. 1954;4:383-91

7. Eckerling B, Teaff R. Obstetrical approach to abdominal war wounds in late pregnancy. J Obstet Gynaecol Br Emp. 1950 Oct;57(5):747-9.

8. Bryant JF, Moore MD. Gunshot wound of the gravid uterus with simultaneous exploration of the mother and fetus. Am Surg. 1964;30:207-8.

9. Mark WJ Ferguson, Sharon O'Kane. Scar free healing from embryonic mechanism to adult therapeutic intervention. Phil Trans R Soc Lond B. 2004;359:839-50.

10. Ashroft GS, Horan MA, Ferguson MW. Ageing is associated with reduced deposition of specific extracellular matrix component, an upregulation of angiogenesis, and an altered inflammatory responsein a murine incisional wound healing. $\mathrm{J}$ Invest Dermatol. 1997 Apr;108(4):430-7. 